\title{
Emergent Networks, Locus of Control, and the Pursuit of Social Capital \\ Michael Stefanone ${ }^{1}$, Jeffery Hancock ${ }^{1}$, Geri Gay ${ }^{1}$ and Anthony Ingraffea ${ }^{2}$ \\ Department of Communication'; Department of Civil and Environmental Engineering ${ }^{2}$, Cornell University
}

\{mas223, jth34,gkg1, ari1\}@cornell.edu

\begin{abstract}
In this paper we examine the relationship between emergent social network characteristics in a computer-supported collaborative learning course and locus of control. An emergent communication network of engineering students that took place in a distributed distance learning environment was examined. Three measures of an actor's social network, density, brokerage, and reach, and participants' locus of control, internal vs. external, were assessed. The data suggest that, relative to participants with external locus of control, participants with internal locus of control decreased their network density over time but increased their brokerage and reach. The results are discussed in the context of instrumental action, through which participants are assumed to develop personal networks in pursuit of maximizing potential social capital.
\end{abstract}

\section{Categories and Subject Descriptors}

K.3.1 [Computers and Education]: Computer uses in Education - collaborative learning, distance learning.

\section{General Terms}

Measurement, Theory.

\section{Keywords}

Social Networks, Instrumental Action, Locus of Control.

\section{INTRODUCTION}

The premise that behavior and action are interpretable only in relation to the positions of actors in social structures underlies much social scientific inquiry. Social structures can be defined as 'persisting patterns of social relationships among social positions' [10]. The traditional network approach focuses on relationships between actors, rather than on the attributes of actors in different social network positions. Indeed, to the best of our knowledge, very little research has examined individual differences and the consequences these differences have with regard to emergent network properties. This question, however, has become increasingly important as collaborative groups become much more likely to be mediated by communication technology. Although previous studies have focused on distributed

Permission to make digital or hard copies of all or part of this work for personal or classroom use is granted without fee provided that copies are not made or distributed for profit or commercial advantage and that copies bear this notice and the full citation on the first page. To copy otherwise, or republish, to post on servers or to redistribute to lists, requires prior specific permission and/or a fee. CSCW'04, November 6-10, 2004, Chicago, Illinois, USA.

Copyright 2004 ACM 1-58113-810-5/04/0011 ..\$5.00. collaborative groups [2], and group histories [17], few have focused on the implications of individual differences on the characteristics of group participation.

The present study answers a call for research on the origins of network positions and the influence of individual characteristics [5]. Specifically, the network composition of senior undergraduate students participating in a distributed engineering class was examined in the context of locus of control and its role in facilitating social capital. Our central assumption is that social actors that rationally pursue social network contacts should develop social networks that enhance access to social capital.

\section{LITERATURE REVIEW}

In the following discussion, social network analytical approaches are first laid out, followed by a description of the notion of social capital and the theory of instrumental action, which we propose is a key guiding theoretical framework from which to approach the study of computer-supported collaborative learning and work groups. Finally, we discuss the concept of locus of control, and its potential role in using social networks to maximize social capital, and the implications for computer-supported collaborative work groups.

\subsection{Social Network Analysis}

In general, the focus of social network studies is on the relationships between social entities. Patterns of relationships are referred to as structure, and structural variables quantify relationships in networks [9].

\subsubsection{Ego Networks}

Abstractions of social network structures centered on an individual are known as 'ego centered' networks, and include social relationships of all kinds [14]. In pursuing an egocentric approach to network analysis, the breadth and intensity of social relationships are measured for a group of individuals, resulting in a collection of ego networks, one for each individual studied. Thus, ego refers to a focal actor in a given network [19]. An ego-centric network can also be conceptualized as a representation of an individual's potential sphere of influence. The range of an ego network represents the breadth, or variety of one's social network.

Within ego networks, social relationships differ in contact intensity. Strong tie contacts are characterized by frequent, reciprocal communication, and include resources for social and emotional support. Often, strong ties constitute relationships with family and close friends. Weak ties, on the other hand, are characterized by infrequent communication, low reciprocity, and a lack of emotional closeness. Granovetter's $[7,8]$ seminal work on the 'strength of weak ties' suggests that acquaintances (weak ties) could offer an 
advantage over friends and colleagues (strong ties) in obtaining useful information.

There are at least three useful measures of an ego network: density, reach, and brokerage. The density of a network, in the context of ego-centered networks, focuses on the links that exist among the contacts of ego, or the redundancy of contacts in a network. Wellman [19] used density analysis to examine characteristics of personal networks in urban areas, finding that indeed ego networks covered a wide geographic area. The densest networks were, as expected, composed of kin, or strong ties. While density is a measure of the redundancy of contacts within an ego network, reach indicates an actor's integration, or reach, in a network by identifying the number of actors that are within 2 links of ego (i.e., the number of actors reachable within 2 degrees of separation). Finally, brokerage refers to the frequency that an actor is the only conduit between two other actors. For example, for actors $\mathrm{A}, \mathrm{B}$, and $\mathrm{C}$, where $\mathrm{A}$ knows $\mathrm{B}$, and $\mathrm{B}$ knows $\mathrm{C}, \mathrm{B}$ is in a brokerage position between $A$ and $C$. As such, brokerage represents opportunity for control, and thus can be considered beneficial in the pursuit of instrumental action.

\subsection{Instrumental Action}

Lin's [13] theory of instrumental action describes behaviors that seek to achieve a goal that benefits the person taking the action. These behaviors are defined as instrumental in nature, and are restricted to instrumental actions that involve use of a social contact or resource. Resources embedded in social networks are used to maintain or promote an individual's self interest (survival, wealth). Thus, the theory focuses on instrumental action initiated for the purpose of gaining valued resources that reside in a social system (e.g., gaining access to an executive through a secretary).

Lin's theory also predicts that actors occupying certain network positions have greater access to social resources and, therefore, have greater success using resources for instrumental purposes. For example, people high in a hierarchy (determined by status, prestige, power, etc.) are assumed to have greater accessibility and command of resources by virtue of their network characteristics, such as greater range and visibility of the network. Recall, for example, that weak ties tend to lead to better social resources than strong ties $[7,8]$. Thus, those network positions that have access to many weak ties should facilitate new and diverse information sources. We refer to these types of resources that are derived from social relationships as social capital $[4,12]$.

The question remains, however: are there individual differences that lead certain people to pursue resources embedded in social networks for the purpose of instrumental gain more systematically than others? One possible individual characteristic that may play an important role in this context is locus of control.

\subsection{Locus of Control}

The concept of locus of control suggests that people differ in the degree to which they perceive that they control circumstances affecting their life $[6,1,18]$. In particular, people who are "calculating about their choices, involvements and personal entanglements" tend to have an Internal locus of control [11,p.61]. In general, Internals attribute their accomplishments in life to their own actions. In contrast, those with an external locus of control, believe that outside forces (e.g., luck, powerful others) control their circumstances. For example, externals tend to accept dependency on others more than Internals [16].

More importantly in the present context, Internals tend to be more active information gatherers than Externals, especially when the information had functional utility [16]. This observation suggests a relationship between locus of control and instrumental action. In particular, people who think they can control things behave as though they can. As such, this personal characteristic, in a naturally emerging (i.e. unstructured) social network, should influence the degree to which people position themselves within a network that facilitates instrumental action. For example, Internals should be associated with actively developing their social networks to enhance their access to social capital. Hence, we would expect that people with different locus of control orientations should develop ego networks with different characteristics.

\section{HYPOTHESES}

The ego network indices mentioned above, density, reach, and brokerage, will be used to compare the degree to which Internals and Externals develop their networks in a strategic manner, effectively creating relationships which will maximize their potential to exploit social capital.

With regard to density, which indicates the extent to which an actor's contacts within an ego network know each other, or are redundant, it was expected that over time, Internals' ego density would decrease as they seek out less-redundant and more useful contacts that maximize social capital.

H1. Over time, relative to Externals, Internals' network density will decrease as they pursue network contacts for instrumental gain.

Recall that brokerage refers to the frequency with which an actor connects unrelated actors in a network. Because brokerage affords control over the flow of information and resources within a network, brokerage is indicative of exploitation of network inequality. Because Internals are more likely to seek positions of control, it was hypothesized that Internals would be more likely to develop higher levels of brokerage within their ego network than Externals.

H2. Over time, relative to Externals, Internals should be more likely to occupy high brokerage positions within their network.

Finally, as noted above, an actor's reach among a group of network contacts (i.e. the class) indicates the degree to which an actor can potentially access resources and information in a network. If Internals are more likely to engage in instrumental action in an effort to maximize social capital, Internals should develop greater reach within an emerging network than Externals.

H3. Over time, relative to Externals, Internals should develop greater reach within their network.

\section{METHOD}

A total of 63 students (49 male, 14 female) enrolled in two senior-level engineering classes participated in this study. Students were evenly split between two universities, as the class is a part of a larger project investigating distributed, collaborative groups. Students from both universities attended lectures simultaneously via a codec $\mathrm{A} / \mathrm{V}$ system, and collaborated with each other on the design of thermal protection systems for a next generation reusable launch 
vehicle (space shuttle). Social network measures were assessed three times over the course of the semester. At time $1(\mathrm{t} 1)$, students indicated their current friends on a class roster, and the frequency of interaction with those friends. Halfway through the semester, time 2 (t2), and at the end of the semester, time $3(\mathrm{t} 3)$, students again indicated which students they communicated with, and how often, specifically for class project-related purposes. The resultant frequency data were arranged into matrix format, where an " $\mathrm{x}$ " in a cell formed by the intersection of row $i$ and column $j$ in the matrix meant that actor $\mathrm{i}$ had interacted with actor $\mathrm{j}$ for $\mathrm{x}$ times. This matrix reflected all of the possible pairings between each student.

Students also completed a survey measuring their locus of control [14]. The questionnaire consisted of forced choice items, and was scored such that higher scores represent more externally-oriented locus of control. Each item consists of a pair of alternatives lettered $a$ or $b$, and subjects are requested to answer the one they believe most in. An internally oriented choice could be 'in my case, getting what I want has little or nothing to do with luck,' opposed to an externally oriented choice, such as 'we might just as well decide what to do by flipping a coin.' For each externally oriented choice, the response was given a value of 1 , so high scores represent external orientation. Chronbach's alpha reliability for the scale was $=.93$.

\section{RESULTS}

Social network analyses were completed using Ucinet v.6 [3]. Overall, participants had an average of $6.1(S D=3.4)$ contacts at $\mathrm{t} 1,7.1$ (3.5) at $\mathrm{t} 2$, and $5.7(2.2)$ at $\mathrm{t} 3$. Internal and external locus of control scores were determined by median split $(=6)$, so that students scoring below the median were characterized as internal, and those scoring above the median as external, resulting in 31 internally oriented and 22 externally oriented participants. Due to the small sample size, defining more than two groups of locus of control would substantially reduce statistical power.

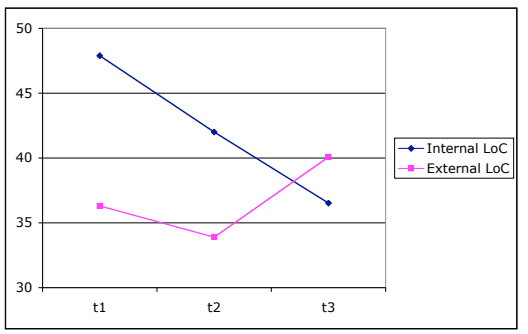

Figure 1. Ego network density change over time.

Ego network density was calculated as the number of ties among an actors ego network divided by the number of pairs, multiplied by 100 . A 3 (time 1 , time 2 , time 3 ) x 2 (Internal vs. External locus of control) mixed general linear model was conducted on the density variable, with time as a repeated measure and locus of control as a between-subjects measure (see Figure 1). Although no main effects were observed, the interaction between time and locus of control was significant, $F(2,98)=3.13, p<.05$. Planned contrasts revealed that Internals had reliably higher levels of network density at times $1, t(49)=2.08, p<.04$, and at time $2, t(51)=2.10, p<.05$, but not at time $3, t(51)=-.52, n s$. Considered together, these data provide support for hypothesis 1. Relative to Externals, Internals decreased their levels of network density over time.

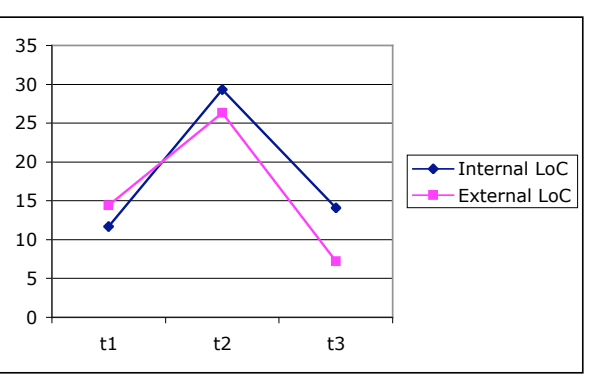

Figure 2. Brokerage frequency change over time.

Ego network brokerage was calculated by counting the frequency which an actor connected two otherwise unconnected actors. A second $3 \times 2$ mixed general linear model was conducted on the brokerage variable (see Figure 2). No effect of locus of control was observed, nor did locus of control interact with the time factor. A main effect of time, however, was observed, $F(1,102)=14.40, p<.001$. Network brokerage opportunity was higher at time 2 than at time 1 , $t(62)=-4.09, p<.001$, and at time $3, t(62)=4.59, p<.001$, suggesting that network brokerage was highest at time 2 . Planned comparisons contrasting Internals vs. Externals at each time point were also conducted, and revealed that although brokerage did not differ across Externals and Internals at time $1, t(51)=-.50, n s$, or time $2, t(51)=.44, n s$, a significant difference was observed at time $3, t(51)=2.40, p<$ .05 , suggesting that, consistent with Hypothesis 2, at the end of the semester Internals had increased their brokerage levels relative to Externals.

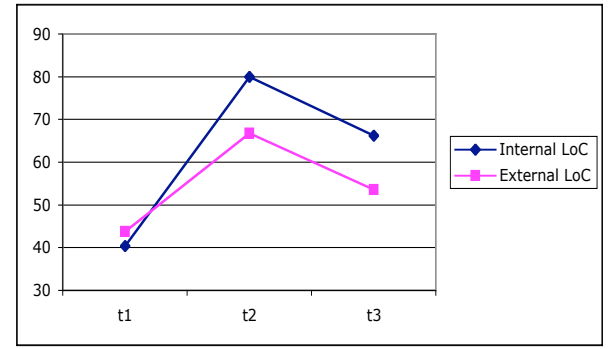

Figure 3. 2 step reach change over time.

Ego network reach was calculated by measuring the proportion of network contacts connected to an actor through 2 links, or 2 degrees of separation. A final $3 \times 2$ mixed general linear model was conducted on the reach variable (see Figure 3). A main effect of time was observed, $F(2,102)=56.12$. Reach levels were higher at time 2 than at time $1, t(62)=-9.39, p<.001$, and at time $3, t(62)=5.14, p<001$, suggesting that, like density, reach was highest at time 2 . This main effect, however, was modified by significant interaction between time and locus of control, $F(2,102)=4.50, p<.05$. Planned comparisons conducted at each time point revealed that at time 1 Externals and Internals did not reliably differ, $t(51)=-.70, n s$, but at both time $2, t(51)=2.11, p<.05$, and at time $3, t(51)=2.69, p$ $<.05$, Internals had higher levels of reach than Externals. Considered together, these data provide support for hypothesis 3, which predicted that relative to Externals, Internals would increase their reach within a social network.

\section{DISCUSSION}

The objective of this study was to determine if individual differences in locus of control result in structural differences 
in ego network composition. In general, we expected that Internal's would be more likely to develop ego networks what facilitate the acquisition of social capital than Externals. In particular, Internal's ego networks were expected to be characterized by low density, high frequency of brokerage and a high level of reach among participants.

As predicted, Internals' network density, although significantly higher then externals at the start of the semester, decreased significantly over the course of the semester. Also, as predicted, Internal's brokerage increased significantly relative to Externals. Finally, with regard to reach, although there was not a significant difference at time 1, at both times 2 and 3, Internals exhibited significantly greater reach than Externals. Considered together, these data suggest that Internals were more likely to develop ego networks that maximize access to social capital. Lower ego network density is important because it reflects the degree to which ties are non-redundant, thus diverse sources of resources [8]. Higher brokerage frequencies indicate greater opportunity for control of resources, which also is positively associated with social capital [12]. Internal's greater reach implies that their immediate social contacts are well integrated into the network as a whole, meaning that their exposure to information flowing through the network is high. These three network attributes suggest strategic pursuit of relationships that provide resources aiding instrumental action, or the augmentation of social capital.

It is also important to note that, consistent with previous research [9], network development peaked at time 2. The drop in brokerage and reach can be attributed to a lack of future interaction at time 3 as the semester came to a close. Although additional research will be required to determine whether Internals ego network compositions actually lead to increased access to social capital, the present study advances our understanding of how individual differences can affect social network structures in distributed, collaborative groups. It appears that actors that believe they control their fate are more likely to actively pursue network contacts for instrumental purposes than people who believe their fate is determined by outside forces. Important questions for future research include identifying other individual differences, such as personality traits, (e.g., conscientiousness), that may also play a role in distributed network structure.

\section{ACKNOWLEDGMENTS}

We gratefully acknowledge the support of NASA Langley Research Center, New York State and the AT\&T Foundation, through Cooperative Agreement No. NCC-1-01004.

\section{REFERENCES}

[1] Blechman, E. A. and Dannemiller, E. A. Effects on performance of perceived control over noxious noise. Journal of Consulting and Clinical Psychology, 44, 601607, 1976.

[2] Bradner, E. and Mark, G. Why distance matters: Effects on cooperation, persuasion and deception. Proceedings of the 2002 CSCW Conference. p. 226-235, 2002.
[3] Borgatti, S. P., Everatt, M. G. and Freeman, L. C. Ucinet for Windows: Software for Social Network Analysis. Harvard: Analytic Technologies, 2002.

[4] Burt, R. S. Structural Holes: The social structure of competition. Cambridge, MA: Harvard University Press, 1992.

[5] Emirbayer, M. and Goodwin, J. Network analysis, culture, and the problem of agency. American Journal of Sociology, 99: 1411-1454, 1994.

[6] Glass, D. C. and Singer, J. E. Urban Stress. New York: Academic Press, 1972.

[7] Granovetter, M. The strength of weak ties. American Journal of Sociology, 78: 1360-1379, 1973.

[8] Granovetter, M. The strength of weak ties: A network theory revisited. In Social Structure and Network Analysis (pp. 105-130), Sage: Beverly Hills, 1982.

[9] Haythornthwaite, C. Exploring multiplexity: Social network structures in a computer-supported distance learning class. The Information Society, 17(3), p.211226, 2001.

[10] Laumann, E. O. Prestige and association in an urban community. Indianapolis: Bobbs-Merrill, 1966.

[11] Lefcourt, H. M. Locus of Control: Current trends in theory and research. New Jersey: Lawrence Erlbaum, 1982.

[12] Lin, N. Building a network theory of social capital. In Social capital: Theory and research, p. 3-30, New York: Aldine de Gruyter, 2001.

[13] Lin, N. Social resources and instrumental action. In Social Structure and Network Analysis, p. 131-145, Beverly Hills, CA: Sage, 1982.

[14] Mitchell, J. C. The concept and use of social networks. In Social Networks in Urban Situations, Manchester: Manchester University Press, p.1-50, 1969.

[15] Rotter, J. B. Generalized expectancies for internal versus external control of reinforcement. Psychological Monographs, 80, 1966.

[16] Seeman, M. Alienation and social learning in a reformatory. American Journal of Sociology, 69, 270284, 1963.

[17] Shen, C., Lesh, N. B., Vernier, F., Forlines, C. and Frost, J. Sharing and building digital group histories. Proceedings of 2002 CSCW Conference, p. 324-333, 2002.

[18] Sherrod, D. R. and Cohen, S. Density, perceived control, and design. In Residential Crowding and Design, New York: Plenum, 1978.

[19] Wellman, B. An egocentric network take. Social Networks, 15, 423-436, 1993. 